\title{
Spectroelectrochemical Characterization of the Active Site of the [FeFe] Hydrogenase HydA1 from Chlamydomonas reinhardtii
}

\author{
Alexey Silakov, ${ }^{*}{ }^{\S}$ Christina Kamp, ${ }^{\S}$ Eduard Reijerse, ${ }^{\S}$ Thomas Happe, ${ }^{\star}$ and Wolfgang Lubitz ${ }^{*}$, \\ ${ }^{\S}$ Max-Planck-Institut für Bioanorganische Chemie, Stiftstr. 34-36, 45470 Mülheim an der Ruhr, Germany, and ${ }^{\star}$ Lehrstuhl Biochemie \\ der Pflanzen, AG Photobiotechnologie, Ruhr Universität Bochum, Universitätsstrasse 150, 44801 Bochum, Germany
}

Received May 29, 2009

\begin{abstract}
Hydrogenases catalyze the reversible oxidation of molecular hydrogen. The active site of the $[\mathrm{FeFe}]$ hydrogenases (H-cluster) contains a catalytically active binuclear subcluster $\left([2 \mathrm{Fe}]_{\mathrm{H}}\right)$ connected to a "cubane" $[4 \mathrm{Fe} 4 \mathrm{~S}]_{\mathrm{H}}$ subcluster. Here we present an IR spectroelectrochemical study of the [FeFe] hydrogenase HydA1 isolated from the green alga Chlamydomonas reinhardtii. The enzyme shows IR bands similar to those observed for bacterial [FeFe] hydrogenases. They are assigned to the stretching vibrations of the $\mathrm{CN}^{-}$and $\mathrm{CO}$ ligands on both irons of the $[2 \mathrm{Fe}]_{\mathrm{H}}$ subcluster. By following changes in frequencies of the IR bands during electrochemical titrations, two one-electron redox processes of the active enzyme could be distinguished. The reduction of the oxidized state $\left(\mathrm{H}_{\mathrm{ox}}\right)$ occurred at a midpoint potential of $-400 \mathrm{mV}$ vs NHE $\left(\mathrm{H}_{\mathrm{ox}} / \mathrm{H}_{\mathrm{red}}\right.$ transition) and relates to a change of the formal oxidation state of the binuclear subcluster. A subsequent reduction $\left(\mathrm{H}_{\mathrm{red}} / \mathrm{H}_{\text {sred }}\right.$ transition) was determined to have a midpoint potential of $-460 \mathrm{mV}$ vs NHE. On the basis of the IR spectra, it is suggested that the oxidation state of the binuclear subcluster does not change in this transition. Tentatively, a reduction of the $[4 \mathrm{Fe} 4 \mathrm{~S}]_{\mathrm{H}}$ cluster has been proposed. In contrast to the bacterial $[\mathrm{FeFe}]$ hydrogenases, where the bridging $\mathrm{CO}$ ligand becomes terminal when going from $\mathrm{H}_{\mathrm{ox}}$ to $\mathrm{H}_{\text {red }}$, in $\mathrm{HydA} 1$ the bridging $\mathrm{CO}$ is present in both the $\mathrm{H}_{\mathrm{ox}}$ and $\mathrm{H}_{\text {red }}$ state. The removal of the bridging $\mathrm{CO}$ moiety has been observed in the $\mathrm{H}_{\text {red }}$ to $\mathrm{H}_{\text {sred }}$ transition. The significance of this result for the hydrogen conversion mechanism of this class of enzymes is discussed.
\end{abstract}

Hydrogenases are enzymes that catalyze the reversible redox reaction $2 \mathrm{H}^{+}+2 \mathrm{e}^{-} \rightleftharpoons \mathrm{H}_{2}$. For this process, they make use of an active site containing the abundant metals nickel and/or iron. Because of the potential application of "hydrogenase like" catalytic systems in hydrogen driven fuel cell technology and hydrogen production systems, scientific interest in the structure and function of hydrogenases has been steadily growing in the last decade $(1,2)$.

On the basis of the metal content of their active site, these enzymes can be divided into three classes: [NiFe], [FeFe], and [Fe] hydrogenases $(1-3)$. [ FeFe] hydrogenases are found in strict anaerobic bacteria and archea. Recently, this class of hydrogenases was also found in green algae, where they become active in energy metabolism under anaerobic conditions (4-7).

[FeFe] hydrogenases contain a total of six iron atoms in their active site, which form the so-called $\mathrm{H}$-cluster $(1,8,9)$. The $[\mathrm{FeFe}]$ hydrogenases from Clostridium pasteurianum $(\mathrm{CpI})^{1}$ and Desulfovibrio desulfuricans $(\mathrm{DdH})$ have been intensively

\footnotetext{
This work was supported by the European Commission (SOLARH2, FP7 contract 212508), the BMBF (Bio-H2, 03SF0355C), and the Max-Planck-Gesellschaft. C.K. and T.H. were further supported by the Deutsche Forschungsgemeinschaft (SFB 480).

*Corresponding authors: (A.S.) Phone: +492083063846; fax: +492083063851; e-mail:silakov@mpi-muelheim.mpg.de; (W.L.) phone: +492083063614; fax: +492083063955; e-mail: lubitz@mpi-muelheim. mpg.de.

${ }^{1} \mathrm{CpI}$, Clostridium pasteurianum $[\mathrm{FeFe}]$ hydrogenase; $\mathrm{DdH}$, Desulfovibrio desulfuricans [FeFe] hydrogenase; HydA1, Chlamydomonas reinhardtii $[\mathrm{FeFe}]$ hydrogenase; EPR, electron paramagnetic resonance spectroscopy; FTIR, Fourier-transform infrared spectroscopy; XAS, Xray absorption spectroscopy; NHE, normal hydrogen electrode.
}

Scheme 1: Representation of the Structure of the H-cluster in the Active Oxidized State

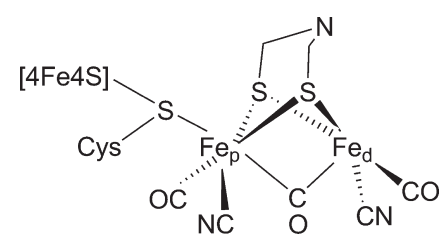

studied by various spectroscopic methods as well as X-ray crystallography $(1,10-12)$. These studies revealed that the $\mathrm{H}$-cluster contains a ferredoxin-like $[4 \mathrm{Fe} 4 \mathrm{~S}]$ cluster $\left([4 \mathrm{Fe} 4 \mathrm{~S}]_{\mathrm{H}}\right)$, connected via a S-Cys to a binuclear subcluster $\left([2 \mathrm{Fe}]_{\mathrm{H}}\right)$. Each iron of the $[2 \mathrm{Fe}]_{\mathrm{H}}$ is coordinated by $\mathrm{CO}$ and $\mathrm{CN}^{-}$ligands $(13-15)$ as depicted in Scheme 1. The iron, located distal to the $[4 \mathrm{Fe} 4 \mathrm{~S}]_{\mathrm{H}}$ $\left(\mathrm{Fe}_{\mathrm{d}}\right)$, has an open coordination site, which is probably involved in binding $\mathrm{H}_{2}(1,16)$. The two iron atoms are connected via a dithiolate bridge.

The exact motif of the dithiolate bridge could not be resolved by X-ray crystallography. Using EPR spectroscopy, it has recently been shown in $\mathrm{DdH}$ that this ligand is a di(thiomethyl)-amine (17).

Up to now, two active redox states of the H-cluster could be identified. In the EPR active "oxidized" state $\left(\mathrm{H}_{\mathrm{OX}}\right)$ the irons of the $[2 \mathrm{Fe}]_{\mathrm{H}}$ are in a $\mathrm{Fe}^{\mathrm{I}} \mathrm{Fe}^{\mathrm{II}}$ mixed valence state $(1,18)$, the open coordination site is either vacant (12) or carries a water molecule (11). In the EPR silent "reduced" state $\left(\mathrm{H}_{\mathrm{red}}\right)$, both irons are in the $\mathrm{Fe}^{\mathrm{I}}$ state (1). Mössbauer data suggested that the formal oxidation state of the $[4 \mathrm{Fe} 4 \mathrm{~S}]_{\mathrm{H}}$ cluster remains at $2+$ in both active states $(19,20)$. 
The H-cluster in its active form can be inhibited by CO, forming an oxidized mixed valence $\mathrm{Fe}^{\mathrm{I}} \mathrm{Fe}^{\mathrm{II}}$ state of the $[2 \mathrm{Fe}]_{\mathrm{H}}$ subcluster, which is abbreviated as $\mathrm{H}_{\mathrm{ox}}-\mathrm{CO}$. In this case the open coordination site at the distal iron is blocked by $\mathrm{CO}$, resulting in an inhibition of the enzyme $(1,10,13)$. In general, the active [FeFe] hydrogenase is quite sensitive to various factors and can be easily damaged, for example, by oxygen or illumination $(15,21)$. This leads to a disintegration of the $\mathrm{H}$-cluster. The released $\mathrm{CO}$ ligands can then inhibit intact $\mathrm{H}$-clusters, thereby generating the $\mathrm{H}_{\mathrm{ox}}-\mathrm{CO}$ state (so-called "cannibalization").

Another state of the H-cluster can be detected during IR spectroelectrochemical reduction. At potentials below $-500 \mathrm{mV}$ vs the normal hydrogen electrode (NHE) the $\mathrm{H}_{\text {red }}$ state converts into the so-called "super" reduced state $\left(\mathrm{H}_{\text {sred }}\right)$. However, this transition was found to be largely irreversible for DdH (15). Moreover, it was found that the $\mathrm{H}_{2}$-production activity of the $\mathrm{CpI}$ enzyme decreases dramatically at reduction potentials below $-425 \mathrm{mV}$ (22). Tentatively, the reduction of the H-cluster to the $\mathrm{H}_{\text {sred }}$ state has been assigned to the reduction of the $[4 \mathrm{Fe} 4 \mathrm{~S}]_{\mathrm{H}}$ cluster, while the oxidation state of the irons in the $[2 \mathrm{Fe}]_{\mathrm{H}}$ subcluster remains unchanged. At $\mathrm{pH} 8.0$ the measured midpoint redox potential of the $\mathrm{H}_{\mathrm{ox}} / \mathrm{H}_{\text {red }}$ transition was $-395 \mathrm{mV}$ vs NHE (15). The midpoint potential for the $\mathrm{H}_{\text {red }} / \mathrm{H}_{\text {sred }}$ reduction was estimated to be about $-540 \mathrm{mV}$. Both transitions were fitted to a Nernstian curve for a one-electron redox reaction $(n=1)$. The $\mathrm{pH}$ dependence of these redox processes showed that both $\mathrm{H}_{\mathrm{ox}} / \mathrm{H}_{\mathrm{red}}$ and $\mathrm{H}_{\mathrm{red}} / \mathrm{H}_{\text {sred }}$ involve one $\mathrm{H}^{+}$.

In the case of $\mathrm{DdH}$, the $\mathrm{H}_{\mathrm{ox}}$ state could not be further oxidized in the spectroelectrochemical cell (15). On the other hand, a report of successful overoxidation of the $[\mathrm{FeFe}]$ hydrogenase from $D$. vulgaris has been presented by van Dijk et al. (23). The overoxidized protein was found to be inactive and oxygen insensitive. The activity was restored under reducing conditions. An anaerobic inactivation has also been observed for $\mathrm{DdH}$ immobilized on a rotating graphite electrode by Vincent et al. $(24,25)$.

So far IR spectra from four [FeFe] hydrogenases have been obtained: D. desulfuricans (15) (DdH), D. vulgaris $(13,26)$, Megasphaera (M.) elsdenii (26), and C. pasteurianum (27). The IR spectra show that the structure of the H-cluster is similar in all $[\mathrm{FeFe}]$ hydrogenases investigated. However, only DdH has been intensively studied by spectroelectrochemistry. Therefore, it is not clear whether all species have the same redox behavior.

In this report we present a spectroelectrochemical characterization of the smallest $[\mathrm{FeFe}]$ hydrogenase, isolated from the unicellular green alga $C$. reinhardtii. The enzyme is nuclear encoded, localized in the chloroplast and only expressed under anaerobic conditions (4). The HydAl protein shows distinct differences to known bacterial [FeFe] hydrogenases (5) for example, the absence of binding motifs for auxiliary FeS clusters. On the other hand, the binding site of the $\mathrm{H}$-cluster was found to be rather similar to bacterial $[\mathrm{FeFe}]$ hydrogenases. Comparison of the amino acid sequence of HydAl with other [FeFe] hydrogenases shows that not only is the binding site of the H-cluster conserved but also part of the second coordination sphere (5). Advances in the purification procedure (28) allowed the first spectroscopic characterization of this type of [FeFe] hydrogenase. An EPR study of HydAl confirmed the presence of the H-cluster (28). The obtained EPR spectra and also the reaction with $\mathrm{CO}$ were found to be similar to DdH and CpI. However, deviations in the $g$-values of the EPR spectra, especially in the CO-inhibited form, indicate slight differences in the electronic structure of the $\mathrm{H}$-cluster between the $[\mathrm{FeFe}]$ hydrogenase from
C. reinhardtii and that from D. desulfuricans (28). A recent XAS study of HydA1 heterologously synthesized in Clostridium acetobutylicum showed that in terms of $\mathrm{Fe}-\mathrm{Fe}$ distances the H-cluster of HydA1 is quite similar to the other [FeFe] hydrogenases studied so far (29).

Here we present a further characterization of the HydAl protein from $C$. reinhardtii by FTIR spectroelectrochemistry. Several redox states of the active HydAl protein could be obtained during spectroelectrochemical reduction. The midpoint potentials of the redox transitions in HydA1 are determined with high accuracy revealing distinct differences to those of DdH $[\mathrm{FeFe}]$ hydrogenase.

\section{MATERIALS AND METHODS}

IR Measurements. Fourier transform IR (FTIR) measurements were performed on a Bruker IFS 66 v/s FTIR spectrometer equipped with a Bruker MCT (mercury cadmium telluride) detector. The spectrometer was controlled by Bruker Opus software on a Windows PC. A constant flow of $\mathrm{N}_{2}$ was led through the sample chamber to expel $\mathrm{CO}_{2}$ gas and water vapor. The spectra were accumulated in the double-sided, forwardbackward mode with either 1000 scans or 2000 scans. All measurements were performed with a resolution of $2 \mathrm{~cm}^{-1}$. The total time of a single measurement was 14 min (1000 scans) or $27 \mathrm{~min}$ (2000 scans). The aperture was set to $2.0 \mathrm{~mm}$. The obtained interferograms were automatically processed by the Opus software utilizing a 32-points phase correction and a Blackman-Harris 3-term apodization window. The baselines of difference IR spectra were corrected using a cubic spline data interpolation procedure applied to manually selected points of the experimental spectra. Data processing was facilitated by home-written routines in the MATLAB programming environment. Overlapping IR bands were resolved via simulation of the experimentally obtained data with a function, which is a linear combination of a Lorentzian and a Gaussian function (so-called pseudo-Voigt function). The ratio between Lorentzian and Gaussian contributions was fitted manually for each component of the IR spectrum.

Spectroelectrochemistry. All experiments were performed using an electrochemical IR cell, originally designed by Moss et al. (30). It contains a $6 \mu \mathrm{m}$ gold mesh ( $70 \%$ transparent) as a working electrode, a Pt counter electrode, and an $\mathrm{Ag} / \mathrm{AgCl}$ reference electrode. The construction of the Moss cell was identical to that used by Fichtner et al. (31). The potential of the $\mathrm{Ag} / \mathrm{AgCl}$ reference electrode was measured before and after each experiment with cyclic voltammetry, using methyl viologen (redox potential $-440 \mathrm{mV}$ vs NHE) as a standard. A mean value was taken for the calibration. In this work all potentials are listed versus the normal hydrogen electrode (NHE). The potential was controlled by a potentiostat from EG\&G instruments (model 283). The uncertainty range of the determination of the midpoint redox potentials was estimated to be $10 \mathrm{mV}$. The temperature was controlled by a thermostat (RML 6, Lauda) and all experiments were performed at $4{ }^{\circ} \mathrm{C}$. Prior to a series of measurements, the IR cell was electrochemically cycled several times with $\mathrm{KCl}$ solution during one day in order to remove oxygen molecules from the gold mesh.

Sample Preparation. HydA1 was isolated and purified as described before (28). All steps were carried out under strict anaerobic conditions in a glovebox (Coy Laboratories, Detroit, USA) in an atmosphere of $99 \% \mathrm{~N}_{2}$ and $1 \% \mathrm{H}_{2}$. The usage of a 
conventional set of mediators such as those used by Albracht et al. (15) resulted in a gradual damage of the sample, making titration data unreliable. The best results were obtained using no mediators at all. The sample solution was prepared by mixing $15 \mu \mathrm{L}$ of $300 \mu \mathrm{M}$ sample with $15 \mu \mathrm{L}$ of $50 \mathrm{mM}$ Tris- $\mathrm{HCl} \mathrm{pH} \mathrm{7.5,}$ $100 \mathrm{mM} \mathrm{KCl}$. The equilibration time of this solution in the Moss cell was determined to be around 10 min (depending on the potential step) by observing changes in the IR spectra and the measured current after changing the potential. The $\mathrm{pH}$ of the Tris buffer was adjusted to 7.5 at $25{ }^{\circ} \mathrm{C}$. Because of the known dependence of the $\mathrm{pH}$ value of Tris buffer on temperature (32), we estimate that the actual $\mathrm{pH}$ of the sample solution during the measurements at $4{ }^{\circ} \mathrm{C}$ was 8.0 .

\section{RESULTS}

In the first step, an IR spectrum of the as-isolated sample was recorded with the potentiostat switched off. The spectrum obtained shows a set of five bands at $2088 \mathrm{~cm}^{-1}, 2072 \mathrm{~cm}^{-1}$, $1964 \mathrm{~cm}^{-1}, 1940 \mathrm{~cm}^{-1}$, and $1800 \mathrm{~cm}^{-1}$ (see Figure 1, negative bands). This set of bands is very similar to the typical IR spectrum of the $\mathrm{H}_{\mathrm{ox}}$ state, obtained from $\mathrm{DdH}$ and $\mathrm{CpI}(15,27)$ and was thus assigned to this state. Additionally, a set of minor bands (2092 $\mathrm{cm}^{-1}, 2084 \mathrm{~cm}^{-1}, 2013 \mathrm{~cm}^{-1}, 1970 \mathrm{~cm}^{-1}, 1810 \mathrm{~cm}^{-1}$ ) was identified and assigned to a small admixture of the $\mathrm{H}_{\mathrm{ox}}-\mathrm{CO}$ state (see Figure S1 in Supporting Information).

This admixture can be attributed to the so-called "cannibalization" effect, described in the introduction. It seems that a similar effect is also present in HydA1. As described for DdH (15), the $\mathrm{H}$-cluster is rather unstable at temperatures above $0^{\circ} \mathrm{C}$, especially under light. The presence of the CO-inhibited state in the asisolated sample of HydA1 was also observed by EPR spectroscopy (28). Applying an initial potential of $-260 \mathrm{mV}$ (vs NHE) resulted in a lowering of the intensities of IR bands corresponding to the $\mathrm{H}_{\mathrm{ox}}$ state, and a moderate increase of IR bands of the $\mathrm{H}_{\mathrm{ox}}-\mathrm{CO}$ state, indicating an additional damage of the sample (see Figure 1 A). However, repeated measurements at the same potential did not show any further damage. Thus, this effect is attributed to a slight degradation of the sample during equilibration of the solution while applying the initial potential.

Lowering of the potential resulted in a decrease of the $\mathrm{H}_{\mathrm{ox}} \mathrm{IR}$ bands and the appearance of another set of bands at $2083 \mathrm{~cm}^{-1}$, $1935 \mathrm{~cm}^{-1}, 1891 \mathrm{~cm}^{-1}$, and $1793 \mathrm{~cm}^{-1}$, which attain a maximum intensity around $-430 \mathrm{mV}$ vs NHE (see Figure 1B). All these IR bands show a similar dependence on the potential and were therefore assigned to a specific state of the $\mathrm{H}$-cluster which we call " $\mathrm{H}_{\text {red" }}$ " In addition, difference spectra revealed only a slight decrease in the intensities of the IR bands of the $\mathrm{H}_{\mathrm{ox}}-\mathrm{CO}$ state. The obtained $\mathrm{H}_{\text {red }}$ state is characterized by the presence of the bridging CO ligand as clearly indicated by a band at $1793 \mathrm{~cm}^{-1}$. Note that in the case of DdH the spectroelectrochemical reduction indicated a shift of the bridging $\mathrm{CO}$ ligand to a terminal position; that is, no bands in the region around $1800 \mathrm{~cm}^{-1}$ have been observed for this enzyme (15). In the case of HydA1 the stretching vibration of the bridging CO ligand just shifts to a lower frequency, apparently, due to a reduction of one of the irons as will be discussed below.

Further reduction leads to a decrease of the $\mathrm{H}_{\text {red }}$ signals. At a potential of $-510 \mathrm{mV}$ the IR spectrum becomes rather simple, containing another set of prominent bands at $2026 \mathrm{~cm}^{-1}$, $2010 \mathrm{~cm}^{-1}, 1954 \mathrm{~cm}^{-1}, 1919 \mathrm{~cm}^{-1}$, and $1882 \mathrm{~cm}^{-1}$ (see Figure $1 \mathrm{C}$ and Figure S1 of Supporting Information). The

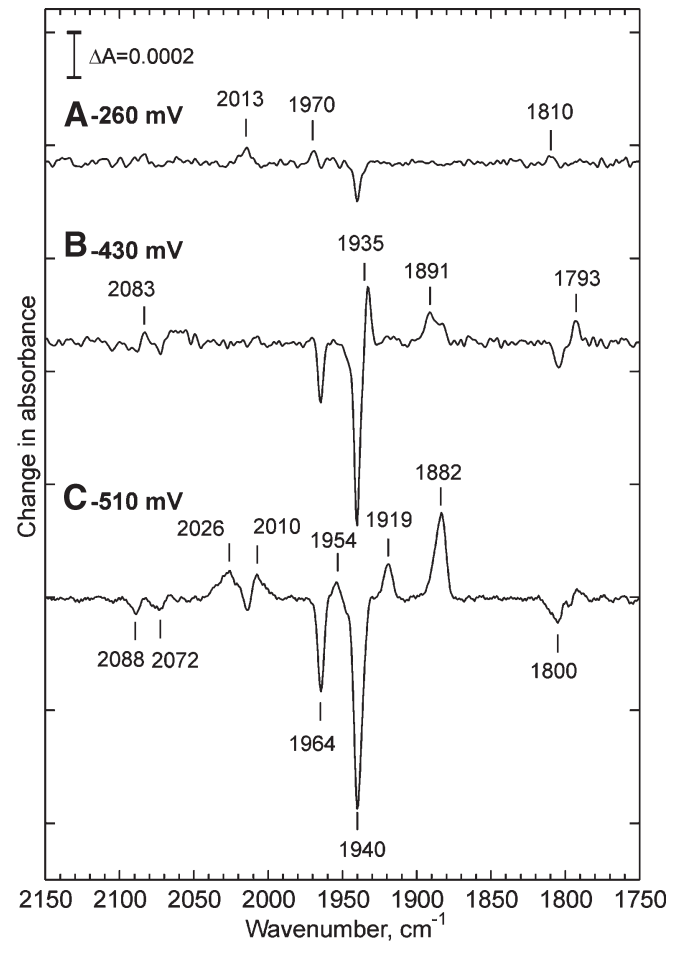

FIgURE 1: Difference FTIR spectra of HydA1 measured at several potentials. The spectrum A is obtained by subtraction from the spectrum recorded with the potentiostat off (negative bands), while spectra $\mathrm{B}$ and $\mathrm{C}$ are subtracted from the IR spectrum taken at $-260 \mathrm{mV}$ (negative bands). Experimental conditions: temperature, $4{ }^{\circ} \mathrm{C}$; resolution, $2 \mathrm{~cm}^{-1}$; number of sample scans, 1000; potential, A $-260 \mathrm{mV} ; \mathrm{B}-430 \mathrm{mV} ; \mathrm{C}-510 \mathrm{mV}$. All spectra were taken during the reductive titration. The numbers above and below the IR spectra indicate the positions of the most prominent bands in $\mathrm{cm}^{-1}$.

intensities of all bands show a similar behavior versus the potential, and therefore these bands can be assigned to a new state. No bands around $1800 \mathrm{~cm}^{-1}$ could be detected for this state. This suggests that in the new state the bridging CO ligand is absent (i.e., it is most probably shifted to a terminal position as will be discussed later). In analogy to the study of $\mathrm{DdH}$, this second reduced state of HydA1 will be termed " $\mathrm{H}_{\text {sred }}$ " ("super reduced" state of the enzyme).

The difference spectra obtained at low potentials did not show any bands at higher frequencies $\left(2100-2060 \mathrm{~cm}^{-1}\right)$ for the $\mathrm{H}_{\text {sred }}$ state. However, an analysis of the original IR spectra showed a band at $2070 \mathrm{~cm}^{-1}$, which is also present at higher potentials and does not change with the $\mathrm{H}_{\text {red }} / \mathrm{H}_{\text {sred }}$ transition (see Figure $\mathrm{S} 1$ in Supporting Information). Since it is overlapping with the band at $2072 \mathrm{~cm}^{-1}$ at higher potentials (a $\mathrm{CN}^{-}$band of the $\mathrm{H}_{\mathrm{ox}}$ state), its behavior with reduction is not clear, making the assignment uncertain. On the other hand, our low temperature study of HydA1 reduced with hydrogen (unpublished data) showed a clear band at $2070 \mathrm{~cm}^{-1}$. Therefore, we are inclined to assign this band to a $\mathrm{CN}^{-}$ligand in both the $\mathrm{H}_{\text {red }}$ and the $\mathrm{H}_{\text {sred }}$ states.

Interestingly, the signals of the contaminating CO-inhibited state also decreased during reduction. This, apparently, indicates a conversion of the $\mathrm{H}_{\mathrm{Ox}}-\mathrm{CO}$ state to a reduced form. Since no other bands have been observed to appear, we can conclude that the sample completely converts to a single state.

In a second set of experiments, the potential has been gradually increased, starting from $-510 \mathrm{mV}$. The appearance and disappearance of IR bands were observed in the reverse manner (see Figure 2B), and the oxidation of $\mathrm{H}_{\text {sred }}$ to $\mathrm{H}_{\text {red }}$ was followed by the 

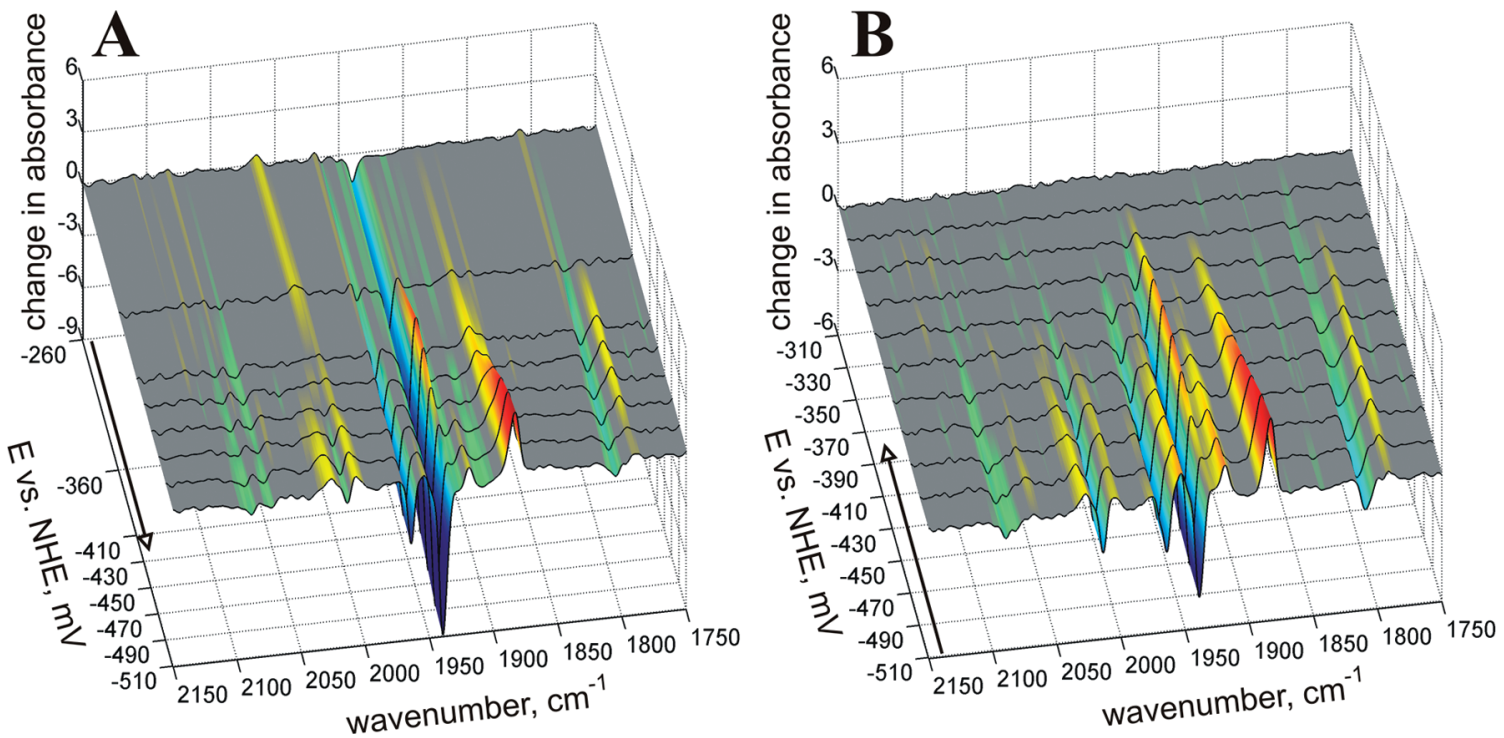

FIGURE 2: Difference FTIR spectra of HydA1, measured during the spectroelectrochemical reduction of the as-isolated state (A) and oxidation of the reduced state (B). Panel A: All spectra were subtracted from the IR spectrum of the as-isolated sample (mainly $\mathrm{H}_{\mathrm{Ox}}$ ). Panel B: All spectra were subtracted from the IR spectrum, measured at $-290 \mathrm{mV}$ (mainly $\mathrm{H}_{\mathrm{ox}}$ ). Experimental conditions: temperature, $4^{\circ} \mathrm{C}$; resolution, $2 \mathrm{~cm}^{-1}$; number of sample scans, 1000 (A), 2000 (B). The arrow below each spectrum shows the direction of the titration.

oxidation of $\mathrm{H}_{\mathrm{red}}$ to $\mathrm{H}_{\mathrm{ox}}$. The $\mathrm{H}_{\mathrm{ox}}$-CO state appears at potentials similar to $\mathrm{H}_{\mathrm{red}}$ and then increases somewhat with the appearance of the $\mathrm{H}_{\mathrm{ox}}$ state. During the oxidation process, the intensities of the $\mathrm{H}_{\text {sred }}$ signals followed a rather similar profile as in the case of reduction. Signals for the $\mathrm{H}_{\text {red }}$ and $\mathrm{H}_{\mathrm{ox}}$ states were somewhat smaller, while the amount of the $\mathrm{H}_{\mathrm{Ox}}-\mathrm{CO}$ state increased (see Supporting Information, Figure S1). This might indicate that the completely reduced form of the H-cluster is rather stable, while the $\mathrm{H}_{\mathrm{red}}$ and the $\mathrm{H}_{\mathrm{ox}}$ states tend to decay over time even at low temperatures $\left(4^{\circ} \mathrm{C}\right)$. It is worth mentioning that in the study of DdH the reduction of the $\mathrm{H}_{\text {red }}$ state to $\mathrm{H}_{\text {sred }}$ was largely irreversible (15).

At potentials between $-300 \mathrm{mV}$ and $-100 \mathrm{mV}$ the measured IR spectra show almost no change. Above $-100 \mathrm{mV}$ a dramatic decrease of the $\mathrm{H}_{\mathrm{OX}}$ bands with an increase of the $\mathrm{H}_{\mathrm{ox}} \mathrm{CO}$ bands is observed, indicating a fast decay of the sample. An additional set of bands has been observed at higher potentials (see Supporting Information, Figure S1) and tentatively attributed to (partially) damaged $\mathrm{H}$-clusters. One could argue that these signals are due to a so-called overoxidized state. However, the titration of the $\mathrm{H}_{\mathrm{Ox}}$ bands at potentials above $-300 \mathrm{mV}$ was best fit to a Nernstian curve with an unrealistic number of participating electrons $(n)$ below 0.5 (data not shown). Moreover, this oxidation process is largely irreversible. On the other hand, a successful anaerobic inactivation at high potentials has been recently observed for HydAl immobilized on a graphite electrode (personal communication, S. Stripp and T. Happe, Ruhr Universität Bochum, Germany). However, in those experiments the time scale of the measurement is much shorter (seconds versus hours in our case). Thus, we are inclined to assume that the enzyme is stable at high potentials for a short time, but then decays over longer periods of time.

Figure 3 shows the titration of the $\mathrm{H}$-cluster as monitored via the IR bands at $1940 \mathrm{~cm}^{-1}, 1935 \mathrm{~cm}^{-1}$, and $1883 \mathrm{~cm}^{-1}$, which corresponds to one of the $\mathrm{CO}$ stretching vibrations in the $\mathrm{H}_{\mathrm{ox}}$, $\mathrm{H}_{\text {red }}$, and $\mathrm{H}_{\text {sred }}$ state, respectively. Changes in the intensities of the IR bands by reduction/oxidation were fitted using the Nernst equation for an one-electron transition $(n=1)$. Following the apparent intensities of the most prominent bands of all observed states, two redox potentials could be extracted: $-400 \mathrm{mV}$ and

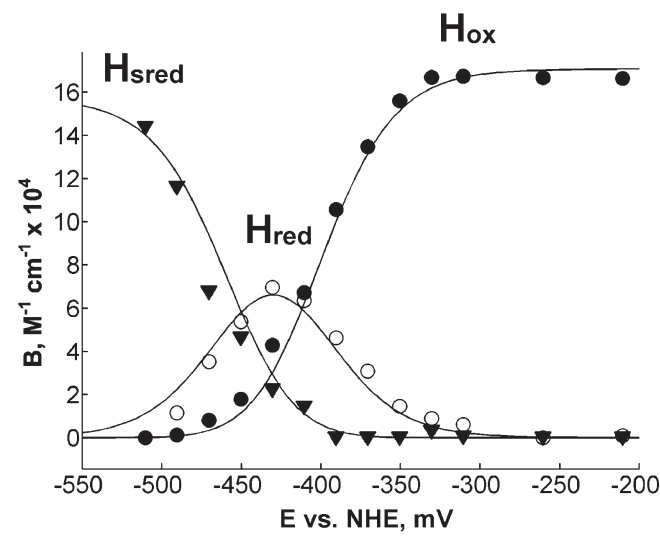

Figure 3: Spectroelectrochemical titration of the [FeFe] hydrogenase from $C$. reinhardtii (HydA1) at $\mathrm{pH} 8.0$ and $T=4.0^{\circ} \mathrm{C}$ as monitored by changes in the apparent intensities of the IR bands at $1883 \mathrm{~cm}^{-1}(\boldsymbol{\nabla}), 1935 \mathrm{~cm}^{-1}(\mathrm{O})$, and $1940 \mathrm{~cm}^{-1}(\mathbf{\bullet})$, corresponding to one of the terminal $\mathrm{CO}$ stretching vibrations of the $\mathrm{H}_{\text {sred }}, \mathrm{H}_{\text {red }}$, and $\mathrm{H}_{\mathrm{ox}}$ state, respectively. The solid lines represent a fit to a Nernstian curve for an one-electron transition $(n=1)$. The midpoint potential for the $\mathrm{H}_{\mathrm{ox}} / \mathrm{H}_{\text {red }}$ transition is $-400 \mathrm{mV}$ (vs NHE) and for the $\mathrm{H}_{\text {red }} /$ $\mathrm{H}_{\text {sred }}$ transition $-460 \mathrm{mV}$ (vs NHE). The experimental conditions are identical to those in Figure 2B.

$-460 \mathrm{mV}$ for the $\mathrm{H}_{\mathrm{ox}} / \mathrm{H}_{\text {red }}$ and the $\mathrm{H}_{\mathrm{red}} / \mathrm{H}_{\text {sred }}$ transitions, respectively. Plots of the changes in the intensities of the various IR bands are presented in Figure 3 together with respective fits. Both directions of the titration resulted in the same redox potentials (see Figure S2 in the Supporting Information).

\section{DISCUSSION}

Analysis of the IR Bands. The observed frequencies of the IR bands of the $\mathrm{CO}$ and $\mathrm{CN}^{-}$stretching vibrations for the various states of the H-cluster are presented in Scheme 2. These vibrations are very sensitive to changes in the charge distribution at the $\mathrm{Fe}$, to which the corresponding ligands are bound. Reduction of the iron makes it more electron rich, increases the $\mathrm{Fe}-\mathrm{CO} / \mathrm{CN}^{-} \pi$-backbonding, and leads to a decrease of the corresponding $\mathrm{CO} / \mathrm{CN}^{-}$stretching vibration frequencies (33). 
Scheme 2: Frequencies of the $\mathrm{CN}^{-}$and $\mathrm{CO}$ Stretching Vibrations (in $\mathrm{cm}^{-1}$ ) of the Various States of the H-cluster as Observed by Spectroelectrochemistry at $4{ }^{\circ} \mathrm{C}$

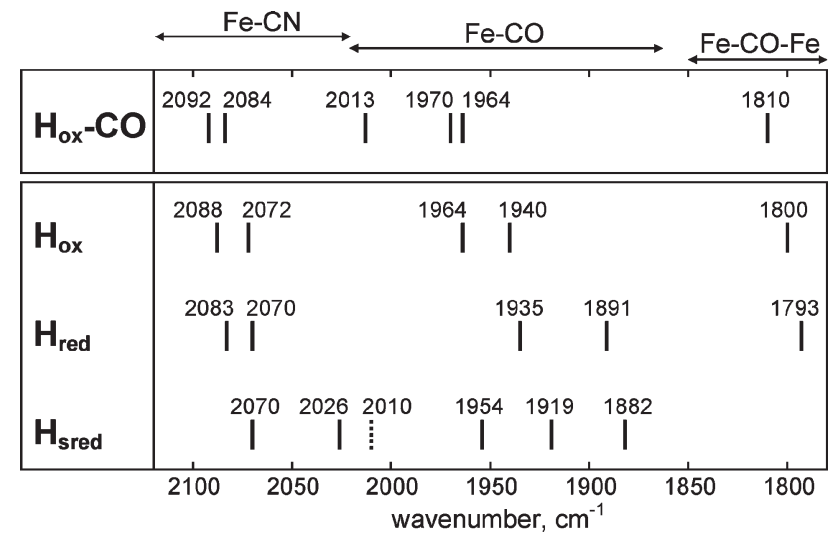

In the case of the $\mathrm{H}_{\mathrm{ox}} / \mathrm{H}_{\text {red }}$ transition, there is a shift in frequencies of both $\mathrm{CO}$ and $\mathrm{CN}^{-}$bands. Since this transition corresponds to an one-electron process, we suggest that it relates to a reduction/oxidation of one of the iron atoms in the binuclear subcluster $\left(\mathrm{Fe}^{\mathrm{I}} \mathrm{Fe}^{\mathrm{II}} \leftrightarrows \mathrm{Fe}^{\mathrm{I}} \mathrm{Fe}^{\mathrm{I}}\right)$. On the other hand, since all $\mathrm{CO}$ and $\mathrm{CN}^{-}$bands shift, no specific assignment of the reduction of any iron is possible based on this data. We can speculate that a shift of both stretching vibrations of the terminal $\mathrm{CN}^{-}$ligands (which are normally decoupled) indicates that the valences of the irons in the $[2 \mathrm{Fe}]_{\mathrm{H}}$ subcluster are mixed to some extent so that a one-electron reduction of the $\mathrm{H}$-cluster may cause a change in the charge distribution of both irons.

In the case of $\mathrm{H}_{\text {sred, }}$, there are three bands in the frequency region between $1960 \mathrm{~cm}^{-1}$ and $1880 \mathrm{~cm}^{-1}$, which is typical for terminal CO ligands. There are no bands in the region of the bridging CO (around $1800 \mathrm{~cm}^{-1}$ ). Therefore, we conclude that the bridging $\mathrm{CO}$ ligand moves to a terminal position at one of the iron atoms during the $\mathrm{H}_{\mathrm{red}} / \mathrm{H}_{\text {sred }}$ transition. In the case of $\mathrm{DdH}$, $\mathrm{X}$-ray crystallography showed that the former bridging $\mathrm{CO}$ ligand moves toward the distal iron leading to a 5 -fold coordination for both irons in the binuclear subcluster. Thus, it is likely that a similar situation occurs in the case of $\mathrm{H}_{\text {sred }}$ in HydA1.

One $\mathrm{CN}^{-}$band $\left(2070 \mathrm{~cm}^{-1}\right)$ remains at the same position during reduction of the $\mathrm{H}_{\text {red }}$ state. The other one apparently moves to a rather low frequency, either to $2028 \mathrm{~cm}^{-1}$ or $2010 \mathrm{~cm}^{-1}$. Since the usual stretching vibration frequencies of the $\mathrm{CN}^{-}$ligands generally lie in a higher frequency region, we tentatively assign the $2028 \mathrm{~cm}^{-1}$ band to $\mathrm{CN}^{-}$. It is worth mentioning that our measurements at cryogenic temperatures (below 200K) did not reveal any prominent bands at $2010 \mathrm{~cm}^{-1}$ for the $\mathrm{H}_{2}$ reduced samples, whereas the $2028 \mathrm{~cm}^{-1}$ band was visible (Silakov, unpublished data). Thus, the nature of the $2010 \mathrm{~cm}^{-1}$ band remains unclear.

The two bands of the terminal CO ligands do not change very much in this transition. It has to be noted that stretching vibrations of $\mathrm{CO}$ ligands are about 3 times more sensitive to a change in the oxidation state of the corresponding iron than those of the $\mathrm{CN}^{-}$ligands. Thus, it is rather unusual to observe a large shift of a $\mathrm{CN}^{-}$band and a much smaller shift of the $\mathrm{CO}$ bands. Therefore, we are inclined to assume that the binuclear site does not change its formal oxidation state in the $\mathrm{H}_{\text {red }} / \mathrm{H}_{\text {sred }}$ transition. We speculate that during this transition the redox reaction takes place at the $[4 \mathrm{Fe} 4 \mathrm{~S}]_{\mathrm{H}}$ cluster, as discussed by Albracht et al. for DdH (15). However, this should result in an EPR active
$[4 \mathrm{Fe} 4 \mathrm{~S}]^{1+}$-containing species, which has not yet been observed. We believe that further experiments using EPR titrations could clarify this point.

The large shift of the $\mathrm{CN}^{-}$band might be a result of a structural rearrangement, rather than changes of charges at any of the irons in the binuclear subcluster. We consider several, possibly complementary, effects:

(i) The $\mathrm{CN}^{-}$ligands are expected to have $\mathrm{H}$-bonds to the nearby amino acids. ${ }^{2}$ A shift of the $\mathrm{CN}^{-}$stretching vibrations toward lower frequencies could thus be a result of weakening or losing the H-bonds. This effect has already been demonstrated for the $[\mathrm{NiFe}]$ hydrogenase from Desulfovibrio fructosovorans. The removal of the $\mathrm{H}$-bonds to the $\mathrm{CN}^{-}$ligands of the [NiFe] active site via mutation of the corresponding serine resulted in a shift of the $\mathrm{CN}^{-}$stretching vibrations to lower frequencies (34). A similar effect has been observed with deprotonation of a [Fe] model complex $(35,36)$. On the other hand, the observed shift of the $\mathrm{CN}^{-}$bands in this model was in the range of $10 \mathrm{~cm}^{-1}$, while in the present case it is much larger (depending on the assignment of the $\mathrm{CN}^{-}$bands either $57 \mathrm{~cm}^{-1}$ or $73 \mathrm{~cm}^{-1}$ ). Therefore, this mechanism cannot explain the observed shift alone. Moreover, losing the $\mathrm{H}$-bond should result in a lower intensity of the $\mathrm{CN}^{-}$ bands due to a decrease of $\pi$-electron acceptability, which is not the case.

(ii) Another reason for a large shift of one of the $\mathrm{CN}^{-}$bands might be a change of the $\mathrm{CO}$ moiety with reduction of the $\mathrm{H}_{\text {red }}$ state to the $\mathrm{H}_{\text {sred }}$ state. During illumination of the $\mathrm{H}_{\mathrm{ox}}-\mathrm{CO}$ state of $\mathrm{DdH}$ at cryogenic temperatures, a transient removal of the bridging $\mathrm{CO}$ ligand has been observed. This resulted in a considerable shift of one of the $\mathrm{CN}^{-}$ligands to lower frequencies due to a redistribution of charge at the irons. Since our results show that the bridging $\mathrm{CO}$ ligand is shifting to a terminal position concomitantly with the reduction of the $\mathrm{H}_{\text {red }}$ state, it could explain the shifts of the $\mathrm{CN}^{-}$band to a lower frequency and some changes in the position of the $\mathrm{CO}$ bands.

(iii) The large shift of the $\mathrm{CN}^{-}$stretching vibration due to the presence of a bound hydride $\mathrm{H}^{-}$has been discussed by Albracht et al. for the case of the $\mathrm{H}_{\text {red }}$ state of $\mathrm{DdH}(15)$. This proposal was based on the observation of a large shift (about $47 \mathrm{~cm}^{-1}$ ) of the stretching vibration frequency of a $\mathrm{CN}^{-}$ligand bound to the $\mathrm{Ni}$ site of the [NiFe] hydrogenase from Ralstonia eutropha upon reduction with $\mathrm{H}_{2}$ (37). Adopting this proposal for the current case, one could speculate that the observed shift of one of the $\mathrm{CN}^{-}$bands to $2028 \mathrm{~cm}^{-1}$ could also be due to binding of a hydride. On the other hand, we expect that the binding of $\mathrm{H}^{-}$ should cause a large shift of the $\mathrm{CO}$ bands as well, which has not been observed. Moreover, in this scenario the $\mathrm{H}_{\text {red }}$ state should have no bound $\mathrm{H}^{-}$, which is in disagreement with current knowledge about this state (I). However, we cannot exclude that the catalytic mechanism in HydA1 differs from that of nonalgal $[\mathrm{FeFe}]$ hydrogenases. Therefore, based solely on our data we cannot completely exclude nor confirm this hypothesis.

Comparison with $\mathrm{DdH}$. We can compare the obtained data with those obtained by Albracht et al. $(15,21)$ for $\mathrm{DdH}$. The first rather distinct difference is that the obtained midpoint potential for the $\mathrm{H}_{\text {red }} / \mathrm{H}_{\text {sred }}$ transition $(-460 \mathrm{mV})$ is much higher than the one obtained for $\mathrm{DdH}(-540 \mathrm{mV})$, although the $\mathrm{H}_{\text {ox }} / \mathrm{H}_{\text {red }}$

\footnotetext{
${ }^{2}$ Since the amino acid sequences around the H-cluster are highly conserved in all $[\mathrm{FeFe}]$ hydrogenases (5), we assume that the $\mathrm{H}$-bonding to the $\mathrm{CN}^{-}$ligands, postulated for $\mathrm{DdH}$ and $\mathrm{CpI}$, is also present in HydAl.
} 
transition takes place at a very similar potential $(-400 \mathrm{mV})$. A general reason for this could be the absence of additional FeS clusters in HydA1 and possible deviations in the structural interaction with the surrounding. There are a large number of studies of the redox properties of various ferredoxin and ferredoxin-like [4Fe4S] clusters in the literature (38). The redox potentials of $[4 \mathrm{Fe} 4 \mathrm{~S}]$ clusters are rather sensitive to many different factors, such as the local surrounding and the polarity of the protein (39). For instance, a strong influence of H-bonding to the sulfurs of [4Fe4S] clusters on the redox potentials has been elucidated by Noodleman and co-workers (40).

Thus, any deviation in the surrounding of the $[4 \mathrm{Fe} 4 \mathrm{~S}]_{\mathrm{H}}$ subcluster would cause a deviation in its redox potential. However, the redox potential of the connected binuclear subcluster is expected to change much less. Therefore, the fact that only the observed midpoint potential of the $\mathrm{H}_{\text {red }} / \mathrm{H}_{\text {sred }}$ transition is considerably different from that of $\mathrm{DdH}$ might additionally support the idea that this redox transition involves oxidation/ reduction of the $[4 \mathrm{Fe} 4 \mathrm{~S}]_{\mathrm{H}}$ subcluster.

A comparison of the frequencies of the IR bands with those, obtained by Albracht et al. (15) for DdH showed that the $\mathrm{H}_{\mathrm{ox}}$ and the $\mathrm{H}_{\mathrm{ox}}-\mathrm{CO}$ states are quite similar in both HydAl and DdH (see Table S1 in Supporting Information). This indicates that the general structure of the active centers of these hydrogenases is very similar. However, the IR spectra corresponding to the $\mathrm{H}_{\text {red }}$ and $\mathrm{H}_{\text {sred }}$ states are rather different. The main observed difference is that the bridging $\mathrm{CO}$ ligand is still present in the $\mathrm{H}_{\text {red }}$ state of HydA1, while it is absent in the $\mathrm{H}_{\text {red }}$ state of DdH. Since it is believed that both $\mathrm{H}_{\mathrm{ox}}$ and $\mathrm{H}_{\text {red }}$ states are involved in the catalytic cycle $(1,16)$, the fact that the $\mathrm{H}_{\mathrm{ox}} / \mathrm{H}_{\text {red }}$ transition does not require an opening of the bridging $\mathrm{CO}$ might be an indication that heterolytic cleavage occurs at the distal iron without involving the formation of a hydride bridge between the two iron atoms of the dinuclear cluster. This coincides with a conclusion from our recent EPR study of the DdH species, in which a nitrogen atom has been identified in the dithiol bridge, hence, supporting the hypothesis of heterolytic $\mathrm{H}_{2}$ cleavage at the distal iron via protonation of the di(thiomethyl)-amine (17). However, since we do not know if the $\mathrm{H}_{\text {sred }}$ state is involved in the catalytic cycle of HydA1 it cannot be completely ruled out that an opening of the $\mathrm{CO}$ bridge plays a role in the mechanism of hydrogen conversion at the H-cluster.

\section{SUMMARY AND CONCLUSION}

For the first time, a spectroelectrochemical IR study has been performed for an algal [FeFe] hydrogenase. The results obtained show that the active center of the $[\mathrm{FeFe}]$ hydrogenase from $C$. reinhardtii is in general similar to other [FeFe] hydrogenases investigated so far. A clear indication of that is the fact that the obtained IR spectra of the $\mathrm{H}_{\mathrm{ox}}$ and $\mathrm{H}_{\mathrm{ox}}-\mathrm{CO}$ states are very similar to those observed for $\mathrm{DdH}$ and $\mathrm{CpI}$. This also coincides with our EPR characterization of this type of enzyme. On the other hand, distinct differences were found. Although the reduction of the $\mathrm{H}_{\mathrm{ox}}$ state to the $\mathrm{H}_{\text {red }}$ state takes place at the same redox potential as in the case of $\mathrm{DdH}$, it does not result in dissociation of the bridging $\mathrm{CO}$ ligand in the case of HydA1 from $C$. reinhardtii. A move of the bridging $\mathrm{CO}$ ligand to a terminal position has been found at much lower potentials, coinciding with a further reduction step. It is proposed that the redox state of the binuclear subcluster does not change during this second reduction; a reduction of the $[4 \mathrm{Fe} 4 \mathrm{~S}]_{\mathrm{H}}$ cluster was tentatively

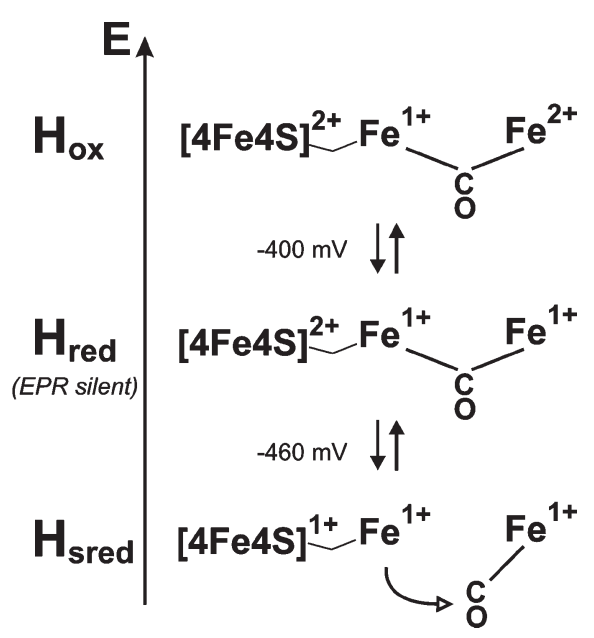

Figure 4: Schematic overview of the observed redox states of the Hcluster of HydA1. The midpoint potential of the redox transition vs NHE, measured at $\mathrm{pH} 8.0$ and a temperature of $4.0^{\circ} \mathrm{C}$, is given. The assignment of the oxidation states of the iron ions in the binuclear subcluster is based on the EPR study for DdH (18). Note that the valences could be delocalized in the binuclear subcluster to some extent.

suggested. A scheme summarizing the discussion is presented in Figure 4.

Another distinct difference between HydA1 and DdH is that the $\mathrm{H}_{\text {red }} / \mathrm{H}_{\text {sred }}$ redox transition takes place at a much higher potential in the algal hydrogenase. It is speculated that this deviation relates to differences in the surrounding of the [4Fe4S] subcluster in these species.

We have shown that although the structure of the H-cluster of HydAl is rather similar to that of other [FeFe] hydrogenases there is a difference in its redox reactions, which might also relate to differences in certain properties such as the catalytic activity.

The fact that the reduction of the $\mathrm{H}_{\mathrm{ox}}$ state does not result in an opening of the bridging $\mathrm{CO}$ ligand indicates that the heterolytic splitting might not require formation of a hydride bridge in the [FeFe] hydrogenase. Thus our data support the hypothesis that the heterolytic cleavage of hydrogen takes place at the external site of the distal iron.

\section{ACKNOWLEDGMENT}

We are very grateful to L. Currell for his technical assistance.

\section{SUPPORTING INFORMATION AVAILABLE}

Absorbance FTIR spectra of HydAl measured at several potentials, a figure of the titration of different IR bands during reduction and oxidation, and a table with comparison of the IR bands observed for HydA1 and DdH. This material is available free of charge via the Internet at http://pubs.acs.org

\section{REFERENCES}

1. Lubitz, W., Reijerse, E., and van Gastel, M. (2007) [NiFe] and [FeFe] hydrogenases studied by advanced magnetic resonance techniques. Chem. Rev. 107, 4331-4365.

2. Vignais, P. M., and Billoud, B. (2007) Occurrence, classification, and biological function of hydrogenases: An overview. Chem. Rev. 107, 4206-4272.

3. Shima, S. (2008) Structure of [Fe]-hydrogenase and the convergent evolution of the active site of hydrogenases. Seikagaku 80, 846-849.

4. Happe, T., and Naber, J. D. (1993) Isolation, characterization and Nterminal amino-acid-sequence of hydrogenase from the green-alga Chlamydomonas reinhardtii. Eur. J. Biochem. 214, 475-481. 
5. Happe, T., and Kaminski, A. (2002) Differential regulation of the Fehydrogenase during anaerobic adaptation in the green alga Chlamydomonas reinhardtii. Eur. J. Biochem. 269, 1022-1032.

6. Florin, L., Tsokoglou, A., and Happe, T. (2001) A novel type of iron hydrogenase in the green alga Scenedesmus obliquus is linked to the photosynthetic electron transport chain. J. Biol. Chem. 276, 61256132.

7. Happe, T., Hemschemeier, A., Winkler, M., and Kaminski, A. (2002) Hydrogenases in green algae: do they save the algae's life and solve our energy problems?. Trends Plant Sci. 7, 246-250.

8. Nicolet, Y., Piras, C., Legrand, P., Hatchikian, C. E., and FontecillaCamps, J. C. (1999) Desulfovibrio desulfuricans iron hydrogenase: the structure shows unusual coordination to an active site Fe binuclear center. Struct. Fold. Des. 7, 13-23.

9. Peters, J. W., Lanzilotta, W. N., Lemon, B. J., and Seefeldt, L. C. (1998) X-ray crystal structure of the Fe-only hydrogenase (Cpl) from Clostridium pasteurianum to 1.8 angstrom resolution. Science 282, $1853-1858$.

10. Lemon, B. J., and Peters, J. W. (1999) Binding of exogenously added carbon monoxide at the active site of the iron-only hydrogenase (CpI) from Clostridium pasteurianum. Biochemistry 38, 12969-12973.

11. Pandey, A. S., Harris, T. V., Giles, L. J., Peters, J. W., and Szilagyi, R. K. (2008) Dithiomethylether as a ligand in the hydrogenase H-cluster. J. Am. Chem. Soc. 130, 4533-4540.

12. Nicolet, Y., de Lacey, A. L., Vernede, X., Fernandez, V. M., Hatchikian, E. C., and Fontecilla-Camps, J. C. (2001) Crystallographic and FTIR spectroscopic evidence of changes in Fe coordination upon reduction of the active site of the Fe-only hydrogenase from Desulfovibrio desulfuricans. J. Am. Chem. Soc. 123, 1596-1601.

13. Pierik, A. J., Hulstein, M., Hagen, W. R., and Albracht, S. P. J. (1998) A low-spin iron with $\mathrm{CN}$ and $\mathrm{CO}$ as intrinsic ligands forms the core of the active site in [Fe]-hydrogenases. Eur. J. Biochem. 258, 572-578.

14. Fontecilla-Camps, J. C., Volbeda, A., Cavazza, C., and Nicolet, Y. (2007) Structure/function relationships of [NiFe]- and [FeFe]-hydrogenases. Chem. Rev. 107, 4273-4303.

15. Roseboom, W., de Lacey, A. L., Fernandez, V. M., Hatchikian, E. C., and Albracht, S. P. J. (2006) The active site of the [FeFe]-hydrogenase from Desulfovibrio desulfuricans. II. Redox properties, light sensitivity and CO-ligand exchange as observed by infrared spectroscopy. $J$. Biol. Inorg. Chem. 11, 102-118.

16. Siegbahn, P. E. M., Tye, J. W., and Hall, M. B. (2007) Computational studies of [NiFe] and [FeFe] hydrogenases. Chem. Rev. 107, 4414 4435.

17. Silakov, A., Wenk, B., Reijerse, E., and Lubitz, W. (2009) ${ }^{14} \mathrm{~N}$ HYSCORE investigation of the H-cluster of [FeFe] hydrogenase: Evidence for a nitrogen in the dithiol bridge. Phys. Chem. Chem. Phys. 11, 6592-6599.

18. Silakov, A., Reijerse, E. J., Albracht, S. P. J., Hatchikian, E. C., and Lubitz, W. (2007) The electronic structure of the H-cluster in the [FeFe]-hydrogenase from Desulfovibrio desulfuricans: A Q-band ${ }^{57} \mathrm{Fe}-$ ENDOR and HYSCORE study. J. Am. Chem. Soc. 129, 1144711458.

19. Popescu, C. V., and Munck, E. (1999) Electronic structure of the H cluster in [Fe]-hydrogenases. J. Am. Chem. Soc. 121, 7877-7884.

20. Pereira, A. S., Tavares, P., Moura, I., Moura, J. J. G., and Huynh, B. H. (2001) Mossbauer characterization of the iron-sulfur clusters in Desulfovibrio vulgaris hydrogenase. J. Am. Chem. Soc. 123, 2771-2782.

21. Albracht, S. P. J., Roseboom, W., and Hatchikian, E. C. (2006) The active site of the [FeFe]-hydrogenase from Desulfovibrio desulfuricans. I. Light sensitivity and magnetic hyperfine interactions as observed by electron paramagnetic resonance. J. Biol. Inorg. Chem. 11, 88-101.

22. Fernandez, V. M., Munilla, R., and Ballesteros, A. (1982) Influence of the redox potential on the activity of Clostridium pasteurianum and chromatium hydrogenases. Arch. Biochem. Biophys. 215, 129-135.

23. van Dijk, C., van Berkel-Arts, A., and Veeger, C. (1983) The effect of re-oxidation on the reduced hydrogenase of Desulfovibrio vulgaris strain Hildenborough and its oxygen stability. FEBS Lett. 156, 340344.

24. Vincent, K. A., Parkin, A., Lenz, O., Albracht, S. P. J., FontecillaCamps, J. C., Cammack, R., Friedrich, B., and Armstrong, F. A. (2005) Electrochemical definitions of $\mathrm{O}_{2}$ sensitivity and oxidative inactivation in hydrogenases. J. Am. Chem. Soc. 127, 18179-18189.

25. Vincent, K. A., Parkin, A., and Armstrong, F. A. (2007) Investigating and exploiting the electrocatalytic properties of hydrogenases. Chem. Rev. 107, 4366-4413.

26. van der Spek, T. M., Arendsen, A. F., Happe, R. P., Yun, S. Y., Bagley, K. A., Stufkens, D. J., Hagen, W. R., and Albracht, S. P. J. (1996) Similarities in the architecture of the active sites of Ni-hydrogenases and Fe-hydrogenases detected by means of infrared spectroscopy. Eur. J. Biochem. 237, 629-634.

27. Chen, Z. J., Lemon, B. J., Huang, S., Swartz, D. J., Peters, J. W., and Bagley, K. A. (2002) Infrared studies of the CO-inhibited form of the Fe-only hydrogenase from Clostridium pasteurianum I: Examination of its light sensitivity at cryogenic temperatures. Biochemistry 41, 2036-2043.

28. Kamp, C., Silakov, A., Winkler, M., Reijerse, E. J., Lubitz, W., and Happe, T. (2008) Isolation and first EPR characterization of the [FeFe]-hydrogenases from green algae. Biochim. Biophys. Acta 1777, 410-416.

29. Stripp, S., Sanganas, O., Happe, T., and Haumann, M. (2009) The Structure of the Active Site $\mathrm{H}$-Cluster of [FeFe] Hydrogenase from the Green Alga Chlamydomonas reinhardtii Studied by X-ray Absorption Spectroscopy. Biochemistry 48, 5042-5049.

30. Moss, D., Nabedryk, E., Breton, J., and Mantele, W. (1990) Redoxlinked conformational-changes in proteins detected by a combination of infrared-spectroscopy and protein electrochemistry - Evaluation of the technique with cytochrome-c. Eur. J. Biochem. 187, 565-572.

31. Fichtner, C., Laurich, C., Bothe, E., and Lubitz, W. (2006) Spectroelectrochemical characterization of the [NiFe] hydrogenase of Desulfovibrio vulgaris Miyazaki F. Biochemistry 45, 9706-9716.

32. Good, N. E., Winget, G. D., Winter, W., Connolly, T. N., Izawa, S., and Singh, R. M. M. (1966) Hydrogen ion buffers for biological research. Biochemistry 5, 467.

33. Nakamoto, K. (1997) Infrared and Raman Spectra of Inorganic and Coordination Compounds, Theory and Applications in Inorganic Chemistry, John Wiley \& Sons, New York, NY.

34. DeLacey, A. L., Fernandez, V. M., Rousset, M., Cavazza, C., and Hatchikian, E. C. (2003) Spectroscopic and kinetic characterization of active site mutants of Desulfovibrio fructosovorans Ni-Fe hydrogenase. J. Biol. Inorg. Chem. 8, 129-134.

35. Darensbourg, M. Y., Lyon, E. J., and Smee, J. J. (2000) The bioorganometallic chemistry of active site iron in hydrogenases. Coord. Chem. Rev. 206, 533-561.

36. Lai, C. H., Lee, W. Z., Miller, M. L., Reibenspies, J. H., Darensbourg, D. J., and Darensbourg, M. Y. (1998) Responses of the $\mathrm{Fe}(\mathrm{CN})(2)-$ (CO) unit to electronic changes as related to its role in [NiFe]hydrogenase. J. Am. Chem. Soc. 120, 10103-10114.

37. Van der Linden, E., Burgdorf, T., Bernhard, M., Bleijlevens, B., Friedrich, B., and Albracht, S. P. J. (2004) The soluble [NiFe]hydrogenase from Ralstonia eutropha contains four cyanides in its active site, one of which is responsible for the insensitivity towards oxygen. J. Biol. Inorg. Chem. 9, 616-626.

38. Bian, S., and Cowan, J. A. (1999) Protein-bound iron-sulfur centers. Form, function, and assembly. Coord. Chem. Rev. 190-192, 10491066.

39. Vassiliev, I. R., Antonkine, M. L., and Golbeck, J. H. (2001) Ironsulfur clusters in type I reaction centers. Biochim. Biophys. Acta 1507, 139-160.

40. Noodleman, L., Lovell, T., Liu, T. Q., Himo, F., and Torres, R. A. (2002) Insights into properties and energetics of iron-sulfur proteins from simple clusters to nitrogenase. Curr. Opin. Chem. Biol. 6, 259273. 